\title{
Transradial vs. Transfemoral Percutaneous Coronary Intervention in Patients With or Without High Bleeding Risk Criteria
}

\author{
Ko Yamamoto, MD; Masahiro Natsuaki, MD; Takeshi Morimoto, MD; Hiroki Shiomi, MD; \\ Hirotoshi Watanabe, MD; Kyohei Yamaji, MD; Hiroki Watanabe, MD; Takao Kato, MD; \\ Naritatsu Saito, MD; Kenji Ando, MD; Kazushige Kadota, MD; Yutaka Furukawa, MD; \\ Takeshi Kimura, MD for the CREDO-Kyoto PCI/CABG Registry Cohort-2 Investigators
}

Background: The transradial approach is reportedly associated with reduced bleeding complications and mortality after percutaneous coronary intervention $(\mathrm{PCl})$. It is unknown whether the clinical benefits of transradial vs. transfemoral $\mathrm{PCl}$ differ between high bleeding risk (HBR) and non-HBR patients.

Methods and Results: After excluding patients with acute myocardial infarction, dialysis, and a transbrachial approach from the 13,087 patients undergoing first $\mathrm{PCl}$ in the CREDO-Kyoto Registry Cohort-2, 6,828 patients were eligible for this study. Patients were divided into 2 groups according to bleeding risk based on Academic Research Consortium HBR criteria, and then divided into a further 2 groups according to access site, radial or femoral: HBR-radial, $n=1,054$ (38.3\%); HBR-femoral, $n=1,699$ (61.7\%); non-HBRradial, $n=1,682$ (41.3\%); and non-HBR-femoral, $n=2,393$ (58.7\%). In the HBR group, the 30-day incidence and adjusted risk for major bleeding (1.9\% vs. 4.7\% [P<0.001]; adjusted hazard ratio [aHR] $0.44,95 \%$ confidence interval $[\mathrm{Cl}] 0.26-0.71[\mathrm{P}<0.001])$ and allcause death $(0.3 \%$ vs. $0.9 \%$ [P=0.04]; aHR $0.30,95 \% \mathrm{Cl} 0.07-0.93[\mathrm{P}=0.04])$ were significantly lower in the radial than femoral group. There were no significant differences in the 30-day incidence and adjusted risk for major bleeding $(0.5 \%$ vs. $1.0 \%[P=0.09]$; aHR $0.68,95 \% \mathrm{Cl} 0.30-1.45[\mathrm{P}=0.33])$ or all-cause death (0.1\% vs. $0.1 \%$ [P=0.96]; aHR $1.51,95 \% \mathrm{Cl} 0.19-9.54[\mathrm{P}=0.67])$ between the radial and femoral approaches in the non-HBR group.

Conclusions: Compared with transfemoral PCI, transradial PCI was associated with lower risk for 30-day major bleeding and mortality in HBR but not non-HBR patients.

Key Words: High bleeding risk; Transfemoral; Transradial

A ccording to several randomized trials and metaanalyses, the transradial approach is associated with reduced bleeding complications and even reduced mortality after percutaneous coronary intervention (PCI). ${ }^{\mathbf{1 4}}$ Thus, transradial access has been recommended as the standard approach for PCI in the guidelines of the European Heart Society and Japanese Circulation Society, as well as the scientific statement of the American Heart Association. ${ }^{5-7}$ The benefits associated with transradial access were mostly related to a reduction in major bleeding complications. ${ }^{\mathbf{8}-10}$ These beneficial effects may particularly be prominent in patients with a high bleeding risk (HBR). However, it is unknown whether the clinical benefits of transradial relative to transfemoral PCI differ between HBR and nonHBR patients. Hence, in this study we examined the effects of transradial vs. transfemoral PCI on clinical outcomes in patients with or without HBR, as defined by the Academic Research Consortium (ARC) HBR criteria,11 in a large Japanese database of patients undergoing first coronary revascularization.

\section{Methods}

The research protocol was approved by the relevant review

Received December 13, 2019; revised manuscript received January 30, 2020; accepted February 11, 2020; J-STAGE Advance Publication released online March 17, 2020 Time for primary review: 24 days

Department of Cardiovascular Medicine, Kyoto University Graduate School of Medicine, Kyoto (K. Yamamoto, H.S., Hirotoshi W., T. Kato, N.S., T. Kimura); Department of Cardiovascular Medicine, Saga University, Saga (M.N.); Department of Clinical Epidemiology, Hyogo College of Medicine, Nishinomiya (T.M.); Division of Cardiology, Kokura Memorial Hospital, Kitakyushu (K. Yamaji, K.A.); Division of Cardiology, Japanese Red Cross Wakayama Medical Center, Wakayama (Hiroki W.); Division of Cardiology, Kurashiki Central Hospital, Kurashiki (K.K.); and Department of Cardiovascular Medicine, Kobe City Medical Center General Hospital, Kobe (Y.F.), Japan

Mailing address: Takeshi Kimura, MD, Department of Cardiovascular Medicine, Kyoto University Graduate School of Medicine, 54 Shogoin Kawahara-cho, Sakyo-ku, Kyoto 606-8507, Japan. E-mail: taketaka@kuhp.kyoto-u.ac.jp

ISSN-1346-9843 All rights are reserved to the Japanese Circulation Society. For permissions, please e-mail: cj@j-circ.or.jp 


\begin{tabular}{|c|c|c|c|}
\hline & $\begin{array}{l}\text { Entire cohort } \\
(n=6,828)\end{array}$ & $\begin{array}{l}\text { Radial group } \\
(n=2,736)\end{array}$ & $\begin{array}{l}\text { Femoral group } \\
(n=4,092)\end{array}$ \\
\hline \multicolumn{4}{|l|}{ Major criteria } \\
\hline Long-term anticoagulation & $488(7.1)$ & $189(6.9)$ & $299(7.3)$ \\
\hline Severe $C K D^{A}$ & $255(3.7)$ & $67(2.4)$ & $188(4.6)$ \\
\hline Severe anemia ${ }^{B}$ & $657(9.6)$ & $213(7.8)$ & $444(10.9)$ \\
\hline Thrombocytopeniac & $78(1.1)$ & $23(0.8)$ & $55(1.3)$ \\
\hline Liver cirrhosis & $166(2.4)$ & $64(2.3)$ & $102(2.5)$ \\
\hline Prior hemorrhagic stroke & $113(1.7)$ & $43(1.6)$ & $70(1.7)$ \\
\hline \multicolumn{4}{|l|}{ Minor criteria } \\
\hline Age $\geq 75$ years & $2,114(31.0)$ & $859(31.4)$ & $1,255(30.7)$ \\
\hline Moderate CKD ${ }^{A}$ & $2,246(32.9)$ & $851(31.1)$ & $1,395(34.1)$ \\
\hline Mild anemia ${ }^{B}$ & $1,365(20.0)$ & $548(20.0)$ & $817(20.0)$ \\
\hline Prior ischemic stroke & $689(10.1)$ & $273(10.0)$ & $416(10.2)$ \\
\hline HBR & $2,753(40.3)$ & $1,054(38.5)$ & $1,699(41.5)$ \\
\hline No-HBR & $4,075(59.7)$ & $1,682(61.5)$ & $2,393(58.5)$ \\
\hline 1 minor criterion & $2,201(32.2)$ & $845(30.9)$ & $1,356(33.1)$ \\
\hline No criteria & $1,874(27.4)$ & $837(30.6)$ & $1,037(25.3)$ \\
\hline
\end{tabular}

Data are presented as $\mathrm{n}(\%)$. ${ }^{\text {AS }}$ evere chronic kidney disease (CKD) was defined as estimated glomerular filtration rate (eGFR) $<30 \mathrm{~mL} / \mathrm{min} / 1.73 \mathrm{~m}^{2}$ and not on dialysis; moderate CKD was defined as an eGFR of $30-59 \mathrm{~mL} / \mathrm{min} / 1.73 \mathrm{~m}^{2}$. BSevere anemia was defined as hemoglobin $(\mathrm{Hb})<11 \mathrm{~g} / \mathrm{dL}$; mild anemia was defined as $\mathrm{Hb} 11-12.9 \mathrm{~g} / \mathrm{dL}$ for men and $11-11.9 \mathrm{~g} / \mathrm{dL}$ for women. ${ }^{C}$ Thrombocytopenia was defined as a platelet count $<100 \times 10^{9} / \mathrm{L}$. HBR, high bleeding risk.

boards or ethics committees in all participating centers. Because study enrollment was retrospective, the need for written informed consent from patients was waived; however, patients who declined study participation when contacted for follow-up were excluded. This strategy is concordant with the guidelines for epidemiological studies issued by the Ministry of Health, Labor and Welfare of Japan, and the Kyoto University Graduate School and Faculty of Medicine, Ethics Committee (Reference no. e42).

The Coronary Revascularization Demonstrating Outcome study in Kyoto (CREDO-Kyoto) PCI Registry Cohort-2 is a multicenter registry that enrolled consecutive patients undergoing first coronary revascularization procedures in 26 Japanese centers between January 2005 and December 2007 (Supplementary Appendix 1). ${ }^{\mathbf{1 2}}$ The design and patient enrollment of the CREDO-Kyoto PCI Registry Cohort-2 have been described elsewhere. ${ }^{12}$ In the present study, we compared 30-day clinical outcomes between transradial and transfemoral PCI stratified by ARC-HBR.

During the 3-years enrollment period, 13,144 patients underwent PCI as their first coronary revascularization procedure. The 57 patients who declined to participate in the study were excluded, leaving 13,087 patients in the PCI arm of the registry. A further 4,729 patients with acute myocardial infarction and 397 patients on hemodialysis were excluded because the femoral approach was mostly selected in these patients. In addition, 1,099 patients who were treated via the brachial artery and 34 patients with missing information on the arterial access site were excluded. Consequently, the current study population consisted of 6,828 patients; this is the same study population, in which we previously compared clinical outcomes between transradial and transfemoral PCI.13

The study population was divided into 2 groups based on ARC HBR criteria. ${ }^{11}$ In the present study we modified the ARC HBR definitions because some of the criteria were not exactly captured in the CREDO-Kyoto Registry; specifically, oral anticoagulant medication at discharge from the index hospitalization was regarded as major criterion for long-term oral anticoagulation, liver cirrhosis was considered a major criterion regardless of the presence of portal hypertension, malignancy was excluded from the criteria for HBR because we did not have information as to whether it was active or not, history of hemorrhagic stroke was regarded as a major criterion but we did not have information on recent traumatic intracranial hemorrhage, and a history of all-ischemic stroke was regarded as a minor criterion because we did not have information on its timing. Information regarding a previous history of spontaneous bleeding requiring hospitalization or transfusion, bleeding diathesis, brain arteriovenous malformation, planned major surgery, recent major trauma or surgery, and the use of non-steroidal anti-inflammatory drugs or steroids was not captured in the registry, and so these criteria were regarded as absent. There were missing values for serum creatinine in 61 patients, platelet count in 45 patients, and hemoglobin in 58 patients, and these patients were regarded as not having those HBR criteria (e.g., chronic kidney disease [CKD], thrombocytopenia, and anemia). In the present analysis, patients were regarded as HBR if they had at least 1 major criterion (e.g., severe CKD, thrombocytopenia, severe anemia, liver cirrhosis, prior hemorrhagic stroke, or anticoagulation) or $\geq 2$ minor criteria (e.g., age $\geq 75$ years, mild anemia, prior ischemic stroke, or moderate CKD; Table 1). ${ }^{14}$ Patients in the HBR and non-HBR groups were divided into a further 2 groups according to access site, radial or femoral (see Figure 1): HBR-radial, $n=1,054$ (38.3\%); HBR-femoral, $n=1,699$ $(61.7 \%)$; non-HBR-radial, $n=1,682(41.3 \%)$; and non-HBRfemoral, $n=2,393(58.7 \%)$. The clinical outcomes at 30 days after PCI were compared between the radial and femoral groups in patients with or without ARC-defined HBR. 


\section{CREDO-Kyoto PCI registry cohort-2 13144 patients}

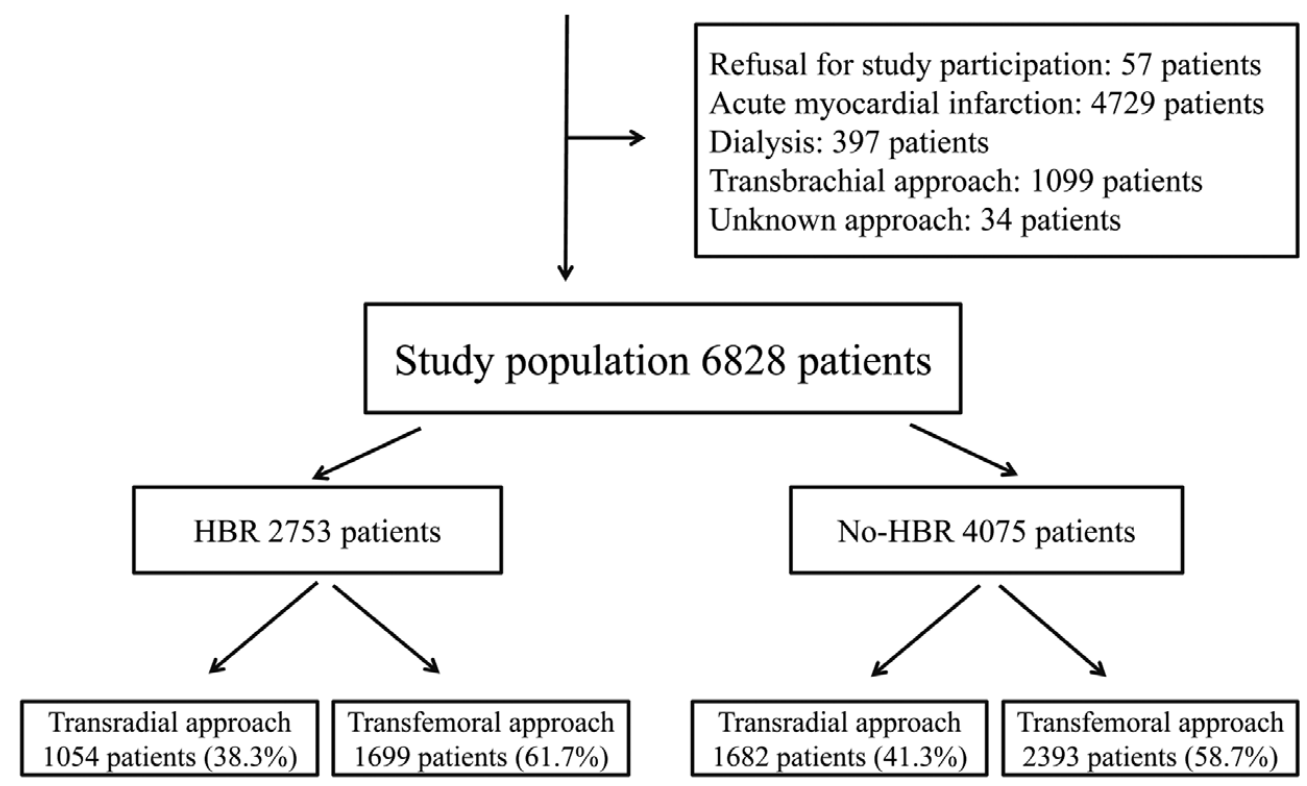

Figure 1. Study patient flow. CREDO-Kyoto, Coronary Revascularization Demonstrating Outcome study in Kyoto; HBR, high bleeding risk; $\mathrm{PCl}$, percutaneous coronary intervention.

Scheduled staged PCI procedures performed during the index hospitalization or within 3 months of the initial procedure were not regarded as follow-up events and were included in the index procedure. The arterial access site of patients who underwent staged PCI procedures was evaluated only at the time of the first PCI procedure. When the initial access site was changed to another site due to arterial puncture failure, only the final access site was recorded in the case report form, and patients were classified based on the final access site. The recommended antiplatelet regimen included aspirin ( $\geq 81 \mathrm{mg}$ daily), which was administered indefinitely, and thienopyridine $(200 \mathrm{mg}$ ticlopidine or $75 \mathrm{mg}$ clopidogrel daily), which was administered for at least 3 months. Unfractionated heparin was used as an antithrombotic agent during PCI, with the dose based on local protocols in the participating centers. No patients were treated with a glycoprotein IIb/IIIa inhibitor or bivalirudin.

Baseline clinical characteristics have been reported elsewhere. ${ }^{12}$ Complex PCI was defined as a procedure with at least 1 of the following angiographic characteristics: 3 vessels treated, $\geq 3$ stents implanted, $\geq 3$ lesions treated, bifurcation with 2 stents implanted, total stent length $>60 \mathrm{~mm}$, or chronic total occlusion as the target lesion. ${ }^{15}$

The primary endpoint was major bleeding, defined as Global Utilization of Streptokinase and Tissue Plasminogen Activator for Occluded coronary arteries (GUSTO) moderate/severe bleeding, at 30 days at the puncture site and/or a non-puncture site. ${ }^{16}$ Procedural bleeding, such as hematoma and retroperitoneal bleeding, was defined as puncture site bleeding, although hematoma size was not measured. Non-puncture site bleeding was classified into the following 5 categories without overlap according to the location and cause of bleeding: intracranial, gastrointestinal, related to surgery, related to PCI, and others. Non-puncture site bleeding related to PCI was defined as PCI procedural bleeding not involving the puncture site (e.g., coronary artery perforation).

Secondary endpoints included death, cardiac death, myocardial infarction, stroke, target lesion revascularization, coronary artery bypass grafting, any coronary revascularization, and major adverse cardiac events (MACE), which consisted of a composite of death, myocardial infarction, or stroke. Death was regarded as cardiac in origin unless obvious non-cardiac causes could be identified. Any death during the index hospitalization was regarded as a cardiac death. Myocardial infarction was defined according to the Arterial Revascularization Therapy Study. ${ }^{17}$ Within 1 week of the index procedure, only Q-wave myocardial infarction was adjudicated as myocardial infarction. Stroke during follow-up was defined as ischemic or hemorrhagic stroke requiring hospitalization with symptoms lasting $>24 \mathrm{~h}$. The definitions of endpoints have been reported elsewhere. ${ }^{\mathbf{1 2 , 1 3}}$ All clinical events were adjudicated by an independent clinical event committee.

Demographic, angiographic, and procedural data were collected from hospital charts or databases in each participating center according to prespecified definitions by experienced clinical research coordinators in the study management center (Supplementary Appendix 2). Follow-up data on clinical events was then collected from hospital charts in the participating centers or from letters and/or telephone calls to patients or referring physicians. The follow-up interval was calculated from the day of the index PCI procedure. 


\section{Statistical Analysis}

Categorical variables are expressed as numbers and percentages and were compared using Chi-squared tests. Continuous variables are expressed as the mean $\pm \mathrm{SD}$ or median and interquartile range (IQR), and were compared using Student's t-test or the Wilcoxon rank-sum test depending on distribution. Cumulative incidence was estimated by the Kaplan-Meier method, and the significance of differences was assessed using the log-rank test. The risk of clinical events in the radial group compared with the femoral group is expressed as hazard ratios (HRs) and 95\% confidence intervals (CIs). HRs were estimated using the Cox proportional hazard models adjusted for 4 clinically relevant factors, namely age ( $\geq 75$ years), sex, urgent procedure, and complex PCI based on clinical relevance (Table 1).

All statistical analyses were conducted using JMP 14.0 (SAS Institute, Cary, NC, USA). All reported P-values are 2-tailed, and $\mathrm{P}<0.05$ was considered significant.

\section{Results}

There were substantial differences in baseline characteristics and medications between the radial and femoral groups, and these differences were generally consistent in the HBR and non-HBR groups. Compared with the radial group, the femoral group included more women, as well as patients with urgent procedures, unstable angina, and more often with comorbidities, such as heart failure and prior myocardial infarction. Among HBR patients, the radial group more often had diabetes, severe CKD, and severe anemia. Peripheral vascular disease was more common in the radial than femoral group. In terms of angiographic and procedural characteristics, the femoral group had significantly more patients with complex characteristics than the radial group. Sheath size and the amount of contrast were greater in the femoral than radial group. Baseline medications were also different between the 2 groups (Table 2).

Among HBR patients, the 30-day incidence of major bleeding was significantly lower in the radial than femoral

\begin{tabular}{|c|c|c|c|c|c|c|}
\hline \multirow[b]{3}{*}{ Clinical characteristics } & \multicolumn{3}{|c|}{ HBR $(n=2,753)$} & \multicolumn{3}{|c|}{ Non-HBR $(n=4,075)$} \\
\hline & $\begin{array}{l}\text { Radial group } \\
(n=1,054)\end{array}$ & $\begin{array}{c}\text { Femoral group } \\
(n=1,699)\end{array}$ & P-value & $\begin{array}{l}\text { Radial group } \\
(n=1,682)\end{array}$ & $\begin{array}{c}\text { Femoral group } \\
(n=2,393)\end{array}$ & P-value \\
\hline & & & & & & \\
\hline Age (years) & $74.8 \pm 8.2$ & $74.2 \pm 9.1$ & 0.07 & $64.3 \pm 9.4$ & $64.6 \pm 9.3$ & 0.3 \\
\hline Age $\geq 75$ years $^{A}$ & $660(63)$ & 977 (58) & 0.008 & 199 (12) & $278(12)$ & 0.83 \\
\hline Men $^{A}$ & $718(68)$ & $1,084(64)$ & 0.02 & $1,337(79)$ & $1,756(73)$ & $<0.001$ \\
\hline $\mathrm{BMI}\left(\mathrm{kg} / \mathrm{m}^{2}\right)$ & $23.1 \pm 3.4$ & $23.2 \pm 3.5$ & 0.63 & $24.5 \pm 3.4$ & $24.4 \pm 3.3$ & 0.35 \\
\hline $\mathrm{BMI}<25.0 \mathrm{~kg} / \mathrm{m}^{2}$ & $780(74)$ & $1,215(72)$ & 0.15 & $1,035(62)$ & $1,453(61)$ & 0.6 \\
\hline Urgent procedure $^{A}$ & 39 (3.7) & $143(8.4)$ & $<0.001$ & $73(4.3)$ & $252(11)$ & $<0.001$ \\
\hline Unstable angina & $70(6.6)$ & $222(13)$ & $<0.001$ & $125(7.4)$ & $328(14)$ & $<0.001$ \\
\hline Hypertension & $930(88)$ & $1,501(88)$ & 0.93 & $1,346(80)$ & $1,977(83)$ & 0.04 \\
\hline Diabetes & $389(37)$ & 729 (43) & 0.002 & $641(38)$ & 920 (38) & 0.83 \\
\hline On insulin therapy & $106(10)$ & $194(11)$ & 0.27 & $109(6.5)$ & $167(7.0)$ & 0.53 \\
\hline Current smoker & $206(20)$ & $349(21)$ & 0.53 & $516(31)$ & $784(33)$ & 0.16 \\
\hline Heart failure & $202(19)$ & $450(26)$ & $<0.001$ & $87(5.2)$ & $176(7.4)$ & 0.005 \\
\hline NYHA Class IV & $27(2.6)$ & $68(4.0)$ & 0.04 & $11(0.7)$ & $19(0.8)$ & 0.61 \\
\hline Prior myocardial infarction & $156(15)$ & $411(24)$ & $<0.001$ & $145(8.6)$ & $343(14)$ & $<0.001$ \\
\hline Prior stroke & $240(24)$ & $389(23)$ & 0.94 & $66(3.9)$ & $84(3.5)$ & 0.49 \\
\hline Prior hemorrhagic stroke & $43(4.1)$ & $70(4.1)$ & 0.96 & $0(0.0)$ & $0(0.0)$ & - \\
\hline Prior ischemic stroke & $207(20)$ & $332(20)$ & 0.95 & $66(3.9)$ & $84(3.5)$ & 0.49 \\
\hline Peripheral vascular disease & $166(16)$ & $176(10)$ & $<0.001$ & $107(6.4)$ & $116(4.9)$ & 0.04 \\
\hline Atrial fibrillation & $158(15)$ & $257(15)$ & 0.92 & $53(3.2)$ & $63(2.6)$ & 0.33 \\
\hline eGFR $\left(\mathrm{mL} / \mathrm{min} / 1.73 \mathrm{~m}^{2}\right)$ & $56.4 \pm 18.1$ & $53.6 \pm 19.9$ & $<0.001$ & $73.8 \pm 15.9$ & $73.1 \pm 30.1$ & 0.41 \\
\hline Moderate $C K D^{B}$ & $594(56)$ & $969(57)$ & 0.73 & 257 (15) & $426(18)$ & 0.03 \\
\hline Severe $C^{\prime} D^{B}$ & $67(6.4)$ & $188(11)$ & $<0.001$ & $0(0.0)$ & $0(0.0)$ & - \\
\hline Mild anemiac & $419(40)$ & $615(36)$ & 0.06 & $129(7.7)$ & $202(8.4)$ & 0.37 \\
\hline Severe anemiac & $213(20)$ & $444(26)$ & $<0.001$ & $0(0.0)$ & $0(0.0)$ & - \\
\hline Platelet count $<100 \times 10^{9} / \mathrm{L}$ & $23(2.2)$ & 55 (3.2) & 0.1 & $0(0.0)$ & $0(0.0)$ & - \\
\hline LVEF & $61.5 \pm 12.8$ & $57.3 \pm 14.6$ & $<0.001$ & $64.4 \pm 10.2$ & $61.6 \pm 11.7$ & $<0.001$ \\
\hline LVEF $\leq 40 \%$ & $73(8.1)$ & $211(15)$ & $<0.001$ & $45(3.1)$ & $113(5.5)$ & $<0.001$ \\
\hline Mitral regurgitation grade $3 / 4$ & $62(5.9)$ & $118(7.0)$ & 0.27 & $24(1.4)$ & $67(2.8)$ & 0.004 \\
\hline COPD & $44(4.2)$ & $90(5.3)$ & 0.18 & $57(3.4)$ & $84(3.5)$ & 0.83 \\
\hline Liver cirrhosis & $64(6.1)$ & $102(6.0)$ & 0.94 & $0(0.0)$ & $0(0.0)$ & - \\
\hline Malignancy & $166(16)$ & $234(14)$ & 0.15 & $117(7.0)$ & $176(7.4)$ & 0.63 \\
\hline
\end{tabular}

(Table 2 continued the next page.) 


\begin{tabular}{|c|c|c|c|c|c|c|}
\hline \multirow{3}{*}{ Procedural characteristics } & \multicolumn{3}{|c|}{ HBR $(n=2,753)$} & \multicolumn{3}{|c|}{ Non-HBR $(n=4,075)$} \\
\hline & \multirow[t]{2}{*}{$\begin{array}{l}\text { Radial group } \\
(n=1,054)\end{array}$} & \multirow[t]{2}{*}{$\begin{array}{c}\text { Femoral group } \\
(n=1,699)\end{array}$} & \multirow[t]{2}{*}{ P-value } & \multirow[t]{2}{*}{$\begin{array}{l}\text { Radial group } \\
(n=1,682)\end{array}$} & \multirow[t]{2}{*}{$\begin{array}{c}\text { Femoral group } \\
(n=2,393)\end{array}$} & \multirow[t]{2}{*}{ P-value } \\
\hline & & & & & & \\
\hline No. target lesions & $1[1-2], 1.46 \pm 0.72$ & $1[1-2], 1.54 \pm 0.82$ & 0.009 & $1[1-2], 1.40 \pm 0.69$ & $1[1-2], 1.53 \pm 0.79$ & $<0.001$ \\
\hline No. target lesions $\geq 3$ & $98(9.3)$ & $189(11)$ & 0.13 & $131(7.8)$ & $277(12)$ & $<0.001$ \\
\hline Multivessel disease & $603(57)$ & $1,137(67)$ & $<0.001$ & $805(48)$ & $1,412(59)$ & $<0.001$ \\
\hline Target of proximal LAD & $582(55)$ & $1,063(63)$ & $<0.001$ & $979(58)$ & $1,491(62)$ & 0.008 \\
\hline Target of unprotected LMCA & $33(3.1)$ & $86(5.1)$ & 0.02 & $30(1.8)$ & 94 (3.9) & $<0.001$ \\
\hline Target of СTO & $79(7.5)$ & $379(22)$ & $<0.001$ & $111(6.6)$ & $619(26)$ & $<0.001$ \\
\hline Target of bifurcation & $315(30)$ & $640(38)$ & $<0.001$ & $551(33)$ & $934(39)$ & $<0.001$ \\
\hline Side-branch stenting & 45 (4.3) & $115(6.8)$ & 0.006 & 75 (4.5) & $159(6.6)$ & 0.003 \\
\hline Target of triple vessel disease & $49(4.7)$ & $102(6.0)$ & 0.13 & $67(4.0)$ & $137(5.7)$ & 0.01 \\
\hline Total no. stents & $1[1-2], 1.89 \pm 1.23$ & $2[1-3], 2.13 \pm 1.42$ & $<0.001$ & $1[1-2], 1.75 \pm 1.15$ & $2[1-3], 2.01 \pm 1.34$ & $<0.001$ \\
\hline Total no. stents $\geq 3$ & $224(21)$ & $449(26)$ & 0.002 & $300(18)$ & $589(25)$ & $<0.001$ \\
\hline Total stent length $>28 \mathrm{~mm}$ & $507(50)$ & $930(58)$ & $<0.001$ & $708(44)$ & $1,229(55)$ & $<0.001$ \\
\hline Total stent length $>60 \mathrm{~mm}$ & $176(17)$ & $380(22)$ & $<0.001$ & $240(14)$ & $505(21)$ & $<0.001$ \\
\hline Minimum stent size $<3.0 \mathrm{~mm}$ & $499(50)$ & $850(53)$ & 0.05 & $679(43)$ & $1,090(48)$ & $<0.001$ \\
\hline Procedural success of $\mathrm{PCl}$ & $1,039(99)$ & $1,633(96)$ & $<0.001$ & $1,660(99)$ & $2,313(97)$ & $<0.001$ \\
\hline DES use & $693(66)$ & $1,140(67)$ & 0.47 & $1,135(67)$ & $1,539(64)$ & 0.04 \\
\hline Sheath size (Fr) & $6.08 \pm 0.43$ & $6.75 \pm 0.58$ & $<0.001$ & $6.13 \pm 0.44$ & $6.71 \pm 0.57$ & $<0.001$ \\
\hline Sheath size $>6 \mathrm{Fr}$ & $132(13)$ & $1,181(70)$ & $<0.001$ & $280(17)$ & $1,611(67)$ & $<0.001$ \\
\hline Contrast amount $(\mathrm{mL})$ & $150[100-200]$ & $187[130-260]$ & $<0.001$ & 150 [110-208] & $195[140-260]$ & $<0.001$ \\
\hline Contrast amount $>175 \mathrm{~mL}$ & $342(32)$ & $872(51)$ & $<0.001$ & $620(37)$ & $1,274(53)$ & $<0.001$ \\
\hline Staged $\mathrm{PCl}$ & $182(17)$ & $374(22)$ & 0.003 & $250(15)$ & $566(24)$ & $<0.001$ \\
\hline Complex PClA & $294(28)$ & $735(43)$ & $<0.001$ & $419(25)$ & $1,052(44)$ & $<0.001$ \\
\hline \multicolumn{7}{|l|}{ Medication at hospital discharge } \\
\hline Thienopyridine & $1,027(97)$ & $1,672(98)$ & 0.07 & $1,647(98)$ & $2,351(98)$ & 0.45 \\
\hline Ticlopidine & $880(83)$ & $1,505(89)$ & $<0.001$ & $1,432(85)$ & $2,140(89)$ & $<0.001$ \\
\hline Clopidogrel & $146(14)$ & $161(9.5)$ & $<0.001$ & $212(13)$ & $203(8.5)$ & $<0.001$ \\
\hline Aspirin & $1,026(97)$ & $1,673(98)$ & 0.04 & $1,664(99)$ & $2,372(99)$ & 0.53 \\
\hline Cilostazol & $99(9.4)$ & $188(11)$ & 0.16 & 149 (8.9) & $271(11)$ & 0.01 \\
\hline Warfarin & $189(18)$ & $299(18)$ & 0.82 & $0(0.0)$ & $0(0.0)$ & - \\
\hline Statins & $481(46)$ & $786(46)$ & 0.75 & $917(55)$ & $1,408(59)$ & 0.006 \\
\hline$\beta$-blockers & $273(26)$ & $555(33)$ & $<0.001$ & $348(21)$ & $587(25)$ & 0.004 \\
\hline ACEI/ARB & $602(57)$ & $991(58)$ & 0.53 & $714(42)$ & $1,196(50)$ & $<0.001$ \\
\hline Proton pump inhibitors & $368(22)$ & $516(22)$ & 0.81 & $269(16)$ & 439 (18) & 0.05 \\
\hline $\mathrm{H}_{2}$ receptor blockers & $259(25)$ & $385(23)$ & 0.25 & $253(24)$ & $448(26)$ & 0.17 \\
\hline
\end{tabular}

Continuous variables are expressed as the mean \pm SD or median [(interquartile range]. Categorical variables are expressed as $\mathrm{n}(\%)$. Complex percutaneous coronary intervention ( $\mathrm{PCl}$ ) was defined as a procedure with at least 1 of the following procedural characteristics: 3 vessels treated, $\geq 3$ stents implanted, $\geq 3$ lesions treated, bifurcation with 2 stents implanted, total stent length $>60 \mathrm{~mm}$, or chronic total occlusion as the target lesion. ${ }^{11}$ ARisk-adjusting variables selected for the Cox proportional hazard models. BSevere CKD was defined as eGFR $<30 \mathrm{~mL} / \mathrm{min} / 1.73 \mathrm{~m}^{2}$ and not on dialysis; moderate CKD was defined as an eGFR of $30-59 \mathrm{~mL} / \mathrm{min} / 1.73 \mathrm{~m}^{2}$. CSevere anemia was defined as $\mathrm{Hb}<11 \mathrm{~g} / \mathrm{dL}$; mild anemia was defined as $\mathrm{Hb} 11-12.9 \mathrm{~g} / \mathrm{dL}$ for men and $11-11.9 \mathrm{~g} / \mathrm{dL}$ for women. ACEl, angiotensin-converting enzyme inhibitor; ARB, angiotensin receptor blocker; BMI, body mass index; COPD, chronic obstructive pulmonary disease; CTO, chronic total occlusion; DES, drug-eluting stent; HBR, high bleeding risk; LAD, left anterior descending; LMCA, left main coronary artery; LVEF, left ventricular ejection fraction; NYHA, New York Heart Association. Other abbreviations as in Table 1.

group (1.9\% vs. $4.7 \%$; $\mathrm{P}<0.001$; Table 3; Figure 2A). After adjusting for confounders, the lower risk of the radial relative to the femoral group for major bleeding remained highly significant (adjusted HR 0.44; 95\% CI 0.26-0.71; $\mathrm{P}<0.001$; Figure 3). The cumulative incidence of puncture site and non-puncture site bleeding was also significantly lower in the radial than femoral group $(0.5 \%$ vs. $1.7 \%$ $[\mathrm{P}=0.002]$ and $1.4 \%$ vs. $3.0 \%[\mathrm{P}=0.006]$, respectively; Table 3; Figure 2A). The excess non-puncture site bleeding in the femoral compared with radial group was primarily driven by the excess bleeding related to surgery and the PCI. The incidence of bleeding related to surgery was significantly higher in the femoral than radial group (Table 3). Of the 16 patients with bleeding related to surgery, $9(57 \%)$ had bleeding associated with coronary artery bypass grafting (CABG). The adjusted risks of the radial relative to the femoral group for puncture site and non-puncture site bleeding remained significant (adjusted HRs 0.29 [95\% CI $0.10-0.69 ; \mathrm{P}=0.004]$ and 0.53 [95\% CI 0.29-0.93; $\mathrm{P}=0.03$ ], respectively; Figure 3). The incidence of all-cause death and cardiac death was significantly lower in the radial than femoral group $(0.3 \%$ vs. $0.9 \%[\mathrm{P}=0.04]$ and $0.2 \%$ vs. $0.7 \%[\mathrm{P}=0.047]$, respectively; Table 3). The adjusted risks of the radial relative to the femoral group for all-cause death and cardiac death also remained significant (adjusted HRs 0.30 [95\% CI 0.07-0.93; $\mathrm{P}=0.04]$ and 0.25 [95\% CI $0.04-0.93 ; \mathrm{P}=0.04]$, respectively; 


\begin{tabular}{|c|c|c|c|c|}
\hline \multirow[b]{3}{*}{ HBR $(n=2,753)$} & \multicolumn{2}{|c|}{ Cumulative 30-day incidence $^{A}$} & \multirow{3}{*}{$\begin{array}{l}\text { Unadjusted HR } \\
(95 \% \mathrm{Cl})^{\mathrm{B}}\end{array}$} & \multirow{3}{*}{ P-value } \\
\hline & Radial group & Femoral group & & \\
\hline & $n=1,054$ & $n=1,699$ & & \\
\hline GUSTO moderate/severe bleeding & $20(1.9)$ & $80(4.7)$ & $0.40(0.24-0.64)$ & $<0.001$ \\
\hline Puncture site bleeding & $5(0.5)$ & $29(1.7)$ & $0.28(0.09-0.65)$ & 0.002 \\
\hline Non-puncture site bleeding & $15(1.4)$ & $51(3.0)$ & $0.47(0.26-0.82)$ & 0.006 \\
\hline Gastrointestinal bleeding & $10(1.0)$ & $15(1.0)$ & $1.06(0.46-2.34)$ & 0.88 \\
\hline Intracranial bleeding & $1(0.1)$ & $5(0.3)$ & $0.31(0.02-1.95)$ & 0.24 \\
\hline Bleeding related to $\mathrm{PCl}$ & $2(0.2)$ & $9(0.5)$ & $0.35(0.05-1.38)$ & 0.14 \\
\hline Bleeding related to surgery & $2(0.2)$ & $14(0.9)$ & $0.23(0.04-0.81)$ & 0.02 \\
\hline All-cause death & $3(0.3)$ & $15(0.9)$ & $0.32(0.07-0.98)$ & 0.04 \\
\hline Cardiac death & $2(0.2)$ & $12(0.7)$ & $0.27(0.04-0.99)$ & 0.047 \\
\hline Myocardial infarction & $17(1.6)$ & $23(1.4)$ & $1.19(0.63-2.22)$ & 0.58 \\
\hline Stroke & $5(0.5)$ & $11(0.7)$ & $0.73(0.23-2.01)$ & 0.56 \\
\hline Death/myocardial infarction/stroke & $22(2.1)$ & $45(2.7)$ & $0.79(0.47-1.30)$ & 0.36 \\
\hline Target lesion revascularization & $15(1.4)$ & $30(1.8)$ & $0.81(0.42-1.47)$ & 0.49 \\
\hline Coronary artery bypass grafting & $3(0.3)$ & $15(0.9)$ & $0.32(0.07-0.97)$ & 0.04 \\
\hline Any coronary revascularization & $18(1.7)$ & $40(2.4)$ & $0.72(0.41-1.24)$ & 0.25 \\
\hline Non-HBR $(n=4,075)$ & $\mathrm{n}=1,682$ & $n=2,393$ & & \\
\hline GUSTO moderate/severe bleeding & $9(0.5)$ & $24(1.0)$ & $0.53(0.23-1.11)$ & 0.09 \\
\hline Puncture site bleeding & $0(0.0)$ & $12(0.5)$ & NA & 0.004 \\
\hline Non-puncture site bleeding & $9(0.5)$ & $12(0.5)$ & $1.07(0.44-2.53)$ & 0.88 \\
\hline Gastrointestinal bleeding & $1(0.1)$ & $4(0.1)$ & $0.36(0.02-2.40)$ & 0.31 \\
\hline Intracranial bleeding & $1(0.1)$ & $1(0.04)$ & $1.42(0.06-36.0)$ & 0.8 \\
\hline Bleeding related to $\mathrm{PCl}$ & $2(0.1)$ & $2(0.1)$ & $1.42(0.17-11.8)$ & 0.73 \\
\hline Bleeding related to surgery & $5(0.3)$ & $2(0.1)$ & $3.56(0.77-24.8)$ & 0.11 \\
\hline All-cause death & $2(0.1)$ & $3(0.1)$ & $0.95(0.13-5.74)$ & 0.96 \\
\hline Cardiac death & $2(0.1)$ & $3(0.1)$ & $0.95(0.13-5.74)$ & 0.96 \\
\hline Myocardial infarction & $17(1.0)$ & $16(0.7)$ & $1.41(0.76-3.02)$ & 0.23 \\
\hline Stroke & $1(0.1)$ & $10(0.4)$ & $0.14(0.01-0.74)$ & 0.02 \\
\hline Death/myocardial infarction/stroke & $19(1.1)$ & $28(1.2)$ & $0.97(0.53-1.72)$ & 0.91 \\
\hline Target lesion revascularization & $19(1.1)$ & $44(1.9)$ & $0.61(0.35-1.04)$ & 0.07 \\
\hline Coronary artery bypass grafting & $7(0.4)$ & $21(0.9)$ & $0.48(0.19-1.07)$ & 0.07 \\
\hline Any coronary revascularization & $23(1.4)$ & $53(2.2)$ & $0.62(0.37-0.99)$ & 0.047 \\
\hline
\end{tabular}

AThe number of patients with the event was counted at 30 days. Cumulative incidence was estimated by the KaplanMeier method censored at 30 days. Data for cumulative incidence is given as $n(\%)$. BUnadjusted hazard ratios (HRs) with $95 \%$ confidence intervals (Cls) were estimated by the Cox proportional hazard model. GUSTO, Global Utilization of Streptokinase and Tissue plasminogen activator for Occluded coronary arteries; HBR, high bleeding risk; NA, not applicable; $\mathrm{PCl}$, percutaneous coronary intervention.

\section{Figure 3).}

Among non-HBR patients, the 30-day incidence of major bleeding was low and not significantly different between the radial and femoral groups $(0.5 \%$ vs. $1.0 \%$, respectively; $\mathrm{P}=0.09$; Table 3; Figure 2B). The incidence of puncture site bleeding was significantly lower in the radial than femoral group $(0.0 \%$ vs. $0.5 \%$; $\mathrm{P}=0.004$; Table 3; Figure 2B). The incidence of non-puncture site bleeding was not significantly different between the radial and femoral groups $(0.5 \%$ vs. $0.5 \%$; $P=0.88$; Table 3; Figure 2B). After adjusting for confounders, the risk of the radial relative to the femoral group for major bleeding remained non-significant (adjusted HR 0.68; 95\% CI 0.30-1.45; P=0.33; Figure 3). The cumulative incidence of all-cause death was low and not significantly different between the 2 groups $(0.1 \%$ vs. $0.1 \% ; \mathrm{P}=0.96$; Table 3). The incidence of stroke was significantly lower in the radial than femoral group, but the adjusted risk of the radial relative to the femoral group for stroke was no longer significant (Table 3; Figure 3). There were no significant interactions between HBR or nonHBR status and the approach site for any clinical event (Figure 3). The results for other endpoints, such as target lesion revascularization, $\mathrm{CABG}$, and any coronary revascularization, are given in Table 3.

\section{Discussion}

The main findings of the present observational study comparing the transradial and transfemoral approaches for PCI stratified by bleeding risk were as follows: (1) compared with the transfemoral approach, the transradial approach was associated with a significantly lower risk for 30-day major bleeding in HBR but not non-HBR patients, although there was no significant interaction between the bleeding risk and the access site; and (2) the transradial approach was associated with lower mortality in HBR patients. 


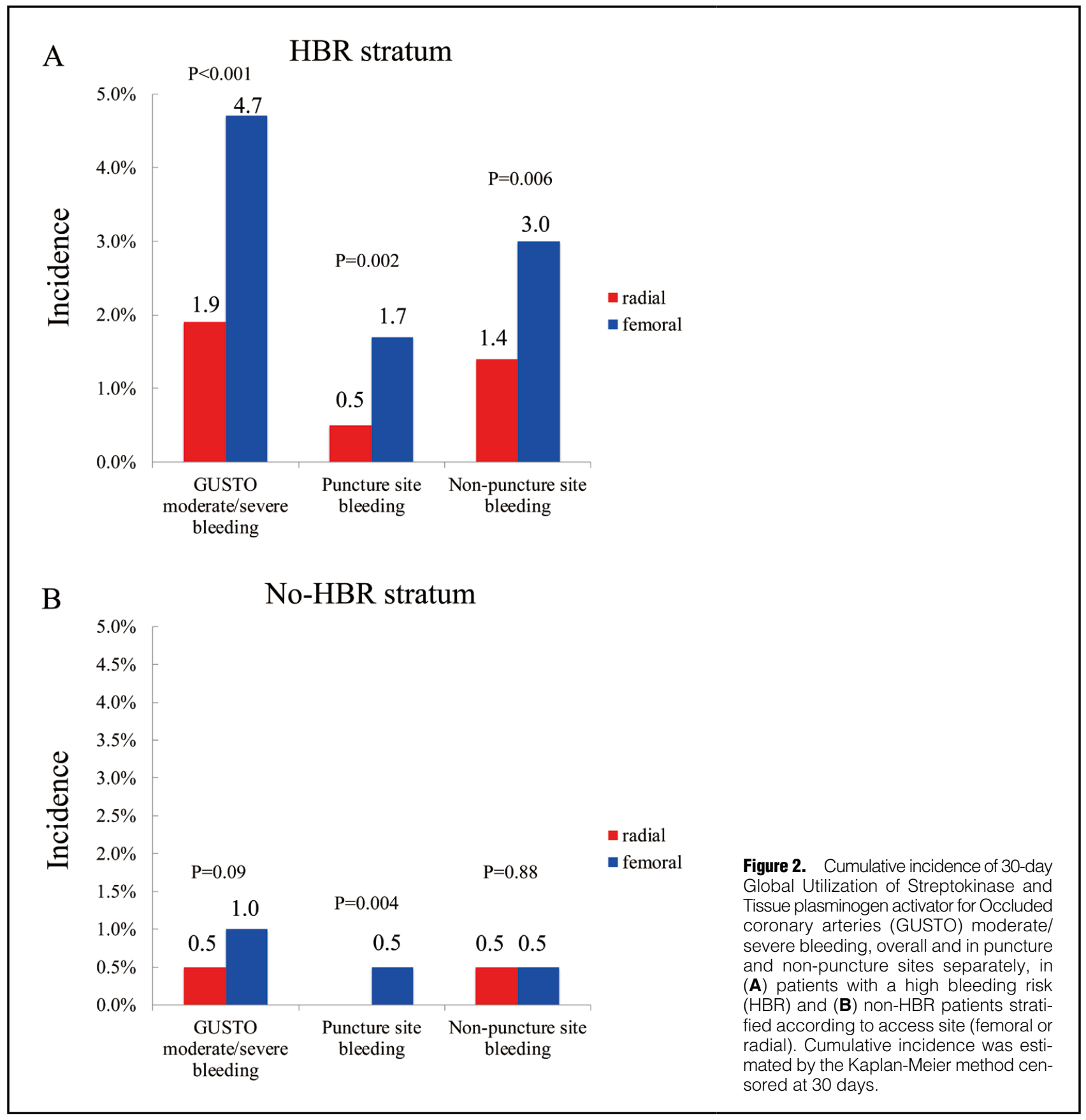

Bleeding complications related to PCI procedures are associated with adverse clinical outcomes, including myocardial infarction, stroke, and death. ${ }^{\mathbf{1 8 - 2 0}}$ Furthermore, periprocedural bleeding is the strongest independent predictor of mortality, with a greater effect on mortality than periprocedural myocardial infarction. ${ }^{\mathbf{2 1 , 2 2}}$ Therefore, it is crucially important to prevent periprocedural bleeding complications to improve clinical outcomes after PCI. In a metaanalysis of randomized trials, Ferrante et al reported that radial access was associated with a significantly lower risk for all-cause mortality (odds ratio [OR] $0.71 ; 95 \%$ CI 0.59 $0.87 ; \mathrm{P}=0.001)$, major bleeding (OR $0.53 ; 95 \%$ CI $0.42-0.65$; $\mathrm{P}<0.001$ ), and major vascular complications (OR $0.23,95 \%$ CI $0.16-0.35 ; \mathrm{P}<0.001) .{ }^{4}$ Mamas et al reported that the transradial approach was associated with reduced 30-day mortality and bleeding, and that the magnitude of this effect was related to baseline bleeding risk calculated by using modified Mehran bleeding scores (MMRS): low $(<10)$ MMRS, OR 0.69, 95\% CI 0.56-0.85, $\mathrm{P}=0.001$; moderate (10-14) MMRS, OR 0.67, 95\% CI 0.57-0.79, $\mathrm{P}<0.0001$; high (15-19) MMRS, OR 0.49, 95\% CI 0.42-0.57, P<0.0001; and very high $(\geq 20) \mathrm{MMRS}$, OR $0.46,95 \%$ CI $0.36-0.59$, $\mathrm{P}<0.0001 .23$ In a previous study we compared clinical outcomes for the transradial and transfemoral approaches in the overall population of the present study. ${ }^{13}$ The 30 -day incidence of access site bleeding was significantly lower in the radial than femoral group, whereas the 30-day incidence of all-cause death was not significantly different between 


\begin{tabular}{|c|c|c|c|c|c|c|c|c|}
\hline & & $\begin{array}{c}\text { Radial group } \\
\mathrm{N} \text { of patients wit } \\
\text { (cumulative } 30\end{array}$ & $\begin{array}{l}\text { Femoral group } \\
\text { th at least } 1 \text { event } \\
\text { )-day incidence) }\end{array}$ & $\begin{array}{r}\text { Favors } \\
\text { Radial group }\end{array}$ & $\begin{array}{l}\text { Favors } \\
\text { Femoral group }\end{array}$ & $\begin{array}{l}\text { Adjusted Hazard } \\
\text { ratio }[95 \% \mathrm{CI}]\end{array}$ & P value & Interaction $\mathrm{P}$ \\
\hline \multirow{2}{*}{$\begin{array}{l}\text { GUSTO moderate/severe } \\
\text { bleeding }\end{array}$} & $\operatorname{HBR}(\mathrm{N}=2753)$ & $20 / 1054(1.9 \%)$ & $80 / 1699(4.7 \%)$ & $\rightarrow$ & & $0.44[0.26-0.71]$ & $<0.001$ & \multirow{2}{*}{0.46} \\
\hline & No-HBR $(\mathrm{N}=4075)$ & $9 / 1682(0.5 \%)$ & $24 / 2393(1.0 \%)$ & & & $0.68[0.30-1.45]$ & 0.33 & \\
\hline \multirow{2}{*}{ Puncture site bleeding } & $\operatorname{HBR}(\mathrm{N}=2753)$ & $5 / 1054(0.5 \%)$ & $29 / 1699(1.7 \%)$ & & & $0.29[0.10-0.69]$ & 0.004 & \multirow{2}{*}{ NA } \\
\hline & No-HBR $(\mathrm{N}=4075)$ & $0 / 1682(0.0 \%)$ & $12 / 2393(0.5 \%)$ & & & NA & & \\
\hline \multirow{2}{*}{ Non-puncture site bleeding } & $\operatorname{HBR}(\mathrm{N}=2753)$ & $15 / 1054(1.4 \%)$ & $51 / 1699(3.0 \%)$ & & & $0.53[0.29-0.93]$ & 0.03 & \multirow{2}{*}{0.1} \\
\hline & No-HBR $(\mathrm{N}=4075)$ & $9 / 1682(0.5 \%)$ & $12 / 2393(0.5 \%)$ & & & $1.30[0.52-3.16]$ & 0.57 & \\
\hline \multirow{2}{*}{ All-cause death } & $\operatorname{HBR}(\mathrm{N}=2753)$ & $3 / 1054(0.3 \%)$ & $15 / 1699(0.9 \%)$ & & & $0.30[0.07-0.93]$ & 0.04 & \multirow{2}{*}{0.31} \\
\hline & No-HBR $(\mathrm{N}=4075)$ & $2 / 1682(0.1 \%)$ & $3 / 2393(0.1 \%)$ & & & $1.51[0.19-9.54]$ & 0.67 & \\
\hline \multirow{2}{*}{ Cardiac death } & $\operatorname{HBR}(\mathrm{N}=2753)$ & $2 / 1054(0.2 \%)$ & $12 / 1699(0.7 \%)$ & $\pi$ & & $0.25[0.04-0.93]$ & 0.04 & \multirow{2}{*}{0.27} \\
\hline & No-HBR $(\mathrm{N}=4075)$ & $2 / 1682(0.1 \%)$ & $3 / 2393(0.1 \%)$ & & & $1.51[0.19-9.54]$ & 0.67 & \\
\hline \multirow{2}{*}{ Myocardial infarction } & $\operatorname{HBR}(\mathrm{N}=2753)$ & $17 / 1054(1.6 \%)$ & $23 / 1699(1.4 \%)$ & & & $1.43[0.74-2.69]$ & 0.28 & \multirow{2}{*}{0.56} \\
\hline & No-HBR $(\mathrm{N}=4075)$ & $17 / 1682(1.0 \%)$ & $16 / 2393(0.7 \%)$ & & $\rightarrow$ & $1.79[0.88-3.66]$ & 0.11 & \\
\hline \multirow{2}{*}{ Stroke } & $\operatorname{HBR}(\mathrm{N}=2753)$ & $5 / 1054(0.5 \%)$ & $11 / 1699(0.7 \%)$ & & - & $1.05[0.33-2.93]$ & 0.93 & \multirow{2}{*}{0.18} \\
\hline & No-HBR $(\mathrm{N}=4075)$ & $1 / 1682(0.1 \%)$ & $10 / 2393(0.4 \%)$ & & _ & $0.19[0.02-1.49]$ & 0.11 & \\
\hline \multirow{3}{*}{$\begin{array}{l}\text { Death/myocardial } \\
\text { infarction/stroke }\end{array}$} & $\operatorname{HBR}(\mathrm{N}=2753)$ & $22 / 1054(2.1 \%)$ & $45 / 1699(2.7 \%)$ & & & $0.95[0.55-1.58]$ & 0.84 & \multirow{2}{*}{0.54} \\
\hline & No-HBR $(\mathrm{N}=4075)$ & $19 / 1682(1.1 \%)$ & $28 / 2393(1.2 \%)$ & & - & $1.20[0.65-2.18]$ & 0.56 & \\
\hline & & & & 0.0625 & 4 & & & \\
\hline
\end{tabular}

Figure 3. Forrest plot for adjusted hazard ratios and $95 \%$ confidence intervals $(\mathrm{Cl})$ of the radial group relative to the femoral group for clinical events. GUSTO, Global Utilization of Streptokinase and Tissue plasminogen activator for Occluded coronary arteries; HBR, high bleeding risk; NA, not applicable.

the 2 groups. In the present study, using the ARC-HBR criteria, the absolute difference in 30-day major bleeding rate between the transradial and transfemoral approaches was much greater in HBR than non-HBR patients, and the transradial approach was also associated with lower mortality in HBR patients. Therefore, the clinical benefits of the transradial approach seem to be greater in HBR than non-HBR patients, suggesting that the transradial approach is preferred particularly in HBR patients.

Andó et al reported that radial access was associated with a reduced risk of acute kidney injury (AKI) compared with femoral access (OR 0.87; 95\% CI 0.77-0.98; $\mathrm{P}=0.0181){ }^{24}$ Pickering et al also reported that acute coronary syndromeassociated AKI was associated with a more than 3-fold increase in 30-day mortality (relative risk 4.1; 95\% CI 3.35.0) ${ }^{25}$ Because moderate or severe CKD is included in the ARC HBR criteria, transradial PCI may reduce the risk of death, especially for those with renal dysfunction, by reducing bleeding complications and $\mathrm{AKI}$.

Mamas et al reported that baseline bleeding risk was not associated with selection of access site in the British Cardiovascular Intervention Society database. ${ }^{23}$ In line with that report, the transradial approach was less often chosen in HBR patients than non-HBR patients in the present study. One of the disadvantages of transradial PCI is the limited guiding catheter size. Indeed, sheath size was significantly larger in the femoral than radial group in the present study. A large guiding catheter provides improved backup support and enables the use of bulky devices, which could be one of the reasons for the higher prevalence of complex lesions in the femoral than radial group. Patients with high thrombotic risks undergoing complex PCI also had a high bleeding risk, leading to the high prevalence of the transfemoral approach in HBR patients. ${ }^{\mathbf{2 6}-28}$ However, the Glidesheath Slender (Terumo, Tokyo, Japan), which combines an inner diameter compatible with a 7-Fr guiding catheter with an outside diameter close to current 6-Fr sheaths, sheath-less catheters, and guide extension catheters, is available in current PCI practice. Therefore, it is getting easier to select the transradial approach even in patients undergoing complex PCI. Another disadvantage of transradial PCI was the higher rate of arterial access failure. ${ }^{29,30}$ However, Nguyen et al reported that ultrasound-guided puncture reduced mean access time ( 93 vs. $111 \mathrm{~s} ; \mathrm{P}=0.009$ ), the mean number 
of attempts ( 1.47 vs. $1.9 ; \mathrm{P}<0.0001)$, and the rate of difficult accesses $(4.5 \%$ vs. $9.2 \% ; \mathrm{P}=0.0007)$ and improved first-pass access $(73 \%$ vs. $59.7 \% ; \mathrm{P}<0.0001) .{ }^{31}$ It would be beneficial to implement the transradial approach more widely in HBR patients requiring complex PCI.

The present study has several limitations. First, the present study was an observational study with limitations inherent to such a study design, including selection bias and unmeasured confounders. Despite substantial differences in the baseline characteristics between the radial and femoral groups, there were limitations in the sample size and the number of events to fully adjust the effects of confounders. Furthermore, we cannot rule out the possibility of an effect of selection bias and residual confounding. The lower incidence of mortality or non-puncture site bleeding in the radial compared with femoral group among HBR patients may be related to differences in patient characteristics rather than to differences in the approach site per se, thus suggesting the presence of residual confounding. Therefore, caution is warranted in interpreting the results of the present study, especially the lower mortality in the radial than femoral group, although the benefit of transradial PCI in the present study is consistent with previous studies. ${ }^{2,4}$ Second, when the initial approach site was changed to another site due to arterial puncture failure, only the final approach site was recorded in the case report form. Thus, we could not evaluate the effect of puncture failure and conversion of approach site. The experience of operators for transradial PCI was unknown. In addition, we did not have information on the long-term patency of the radial artery. Moreover, only the first PCI procedure in each patient was evaluated. Some patients with staged PCI procedures may have undergone both transfemoral and transradial procedures. Third, clinical practice, including selection of the arterial approach site, coronary device, and medical treatment, has changed over time from the period when the present study was conducted to current daily clinical practice. None of the patients in the present study used prasugrel or a non-vitamin $\mathrm{K}$ oral anticoagulant, which are used in current clinical practice. The antithrombotic drugs used at the time of the procedure were unknown. Coronary devices such as the Glidesheath Slender and guide extension catheters were not available during the enrollment period of this study. Fourth, we did not have information regarding the mechanical support devices used, such as intra-aortic balloon pumps and extracorporeal membrane oxygenation. However, the number of patients using mechanical support devices was assumed to be very small because we excluded patients with acute myocardial infarction in the present analysis. Fifth, we did not have information about the use of vascular suturing devices. Sixth, because the CREDO-Kyoto PCI Registry Cohort-2 was not designed to investigate the performance of ARC HBR criteria, data were not available for some ARC HBR criteria. Therefore, the prevalence of HBR patients would have been underestimated in the present study. Seventh, we defined major bleeding as GUSTO moderate/severe bleeding, whereas major bleeding is defined as Bleeding Academic Research Consortium (BARC) Type 3 or 5 in the ARC HBR initiative. However, the rates of major bleeding, defined as either GUSTO moderate/severe or BARC Type 3 or 5 , were reported to be comparable in several previous studies. ${ }^{32,33}$ Finally, we could not investigate the minor puncture site bleeding that did not cause hemodynamic instability or require transfusion, because GUSTO moderate/severe bleeding was defined as a bleeding event in the registry.

In conclusion, compared with transfemoral PCI, transradial PCI was associated with a lower risk for 30-day major bleeding and mortality in HBR patients, as defined by ARC HBR criteria, but not in non-HBR patients.

\section{Acknowledgments}

The authors appreciate the support and collaboration of the coinvestigators participating in the CREDO-Kyoto PCI/CABG Registry Cohort-2. The authors are indebted to the clinical research coordinators for data collection.

\section{Sources of Funding}

This study was supported by the Pharmaceuticals and Medical Devices Agency in Japan.

\section{Conflict of Interest}

The CREDO-Kyoto PCI/CABG Registry Cohort-2 was supported by Pharmaceuticals and Medical Devices Agency in Tokyo, Japan. T. Kimura has served on the advisory board of Abbott Vascular. All other authors have no relationships relevant to the contents of this paper to disclose.

\section{References}

1. Jolly SS, Yusuf S, Cairns J, Niemela K, Xavier D, Widimsky P, et al. Radial versus femoral access for coronary angiography and intervention in patients with acute coronary syndromes (RIVAL): A randomised, parallel group, multicentre trial. Lancet 2011; 377: $1409-1420$.

2. Valgimigli M, Gagnor A, Calabro P, Frigoli E, Leonardi S, Zaro $\mathrm{T}$, et al. Radial versus femoral access in patients with acute coronary syndromes undergoing invasive management: A randomised multicentre trial. Lancet 2015; 385: 2465-2476.

3. Bertrand OF, Belisle P, Joyal D, Costerousse O, Rao SV, Jolly SS, et al. Comparison of transradial and femoral approaches for percutaneous coronary interventions: A systematic review and hierarchical Bayesian meta-analysis. Am Heart J 2012; 163: 632-648.

4. Ferrante G, Rao SV, Juni P, Da Costa BR, Reimers B, Condorelli $\mathrm{G}$, et al. Radial versus femoral access for coronary interventions across the entire spectrum of patients with coronary artery disease: A meta-analysis of randomized trials. JACC Cardiovasc Interv 2016; 9: 1419-1434.

5. Neumann FJ, Chettibi M, Sisakia H, Metzler B, Ibrahimov F, Stelmashok VI, et al. 2018 ESC/EACTS guidelines on myocardial revascularization. Eur Heart J 2018; 00: 1-96.

6. Mason PJ, Shah B, Tamis-Holland JE, Bittl JA, Cohen MG, Safirstein J, et al. An update on radial artery access and best practices for transradial coronary angiography and intervention in acute coronary syndrome: A scientific statement from the American Heart Association. Circ Cardiovasc Interv 2018; 11: $\mathrm{e} 000035$.

7. Kimura K, Kimura T, Ishihara M, Nakagawa Y, Nakao K, Miyauchi K, et al; on behalf of the Japanese Circulation Society Joint Working Group. JCS 2018 guideline on diagnosis and treatment of acute coronary syndrome. Circ J 2019; 83: 1085-1196.

8. Rao SV, Ou FS, Wang TY, Roe MT, Brindis R, Rumsfeld JS, et al. Trends in the prevalence and outcomes of radial and femoral approaches to percutaneous coronary intervention: A report from the National Cardiovascular Data Registry. JACC Cardiovasc Interv 2008; 1: 379-386.

9. Hamon M, Coutance G. Transradial intervention for minimizing bleeding complications in percutaneous coronary intervention. Am J Cardiol 2009; 104: 55C-59C.

10. Chase AJ, Fretz EB, Warburton WP, Klinke WP, Carere RG, Pi $\mathrm{D}$, et al. Association of the arterial access site at angioplasty with transfusion and mortality: The MORTAL study (Mortality benefit Of Reduced Transfusion after percutaneous coronary intervention via the Arm or Leg). Heart 2008; 94: 1019-1025.

11. Urban P, Mehran R, Colleran R, Angiolillo DJ, Byrne RA, Capodanno D, et al. Defining high bleeding risk in patients undergoing percutaneous coronary intervention: A consensus document from the Academic Research Consortium for High Bleeding Risk. Circulation 2019; 140: 240-261.

12. Kimura T, Morimoto T, Furukawa Y, Nakagawa Y, Kadota K, Iwabuchi M, et al. Long-term safety and efficacy of sirolimus- 
eluting stents versus bare-metal stents in real world clinical practice in Japan. Cardiovasc Interv Ther 2011; 26: 234-245.

13. Natsuaki M, Morimoto T, Furukawa Y, Nakagawa Y, Kadota $\mathrm{K}$, Iwabuchi M, et al. Comparison of 3-year clinical outcomes after transradial versus transfemoral percutaneous coronary intervention. Cardiovasc Interv Ther 2012; 27: 84-92.

14. Natsuaki M, Morimoto T, Shiomi H, Yamaji K, Watanabe H, Shizuta S, et al. Application of the Academic Research Consortium high bleeding risk criteria in an all-comers registry of percutaneous coronary intervention. Circ Cardiovasc Interv 2019; 12: $\mathrm{e} 008307$.

15. Giustino G, Chieffo A, Palmerini T, Valgimigli M, Feres F, Abizaid A, et al. Efficacy and safety of dual antiplatelet therapy after complex PCI. J Am Coll Cardiol 2016; 68: 1851-1864.

16. Topol E, Califf R, Vandewerf F, Armstrong PW, Aylward P, Barbash $\mathrm{G}$, et al. An international randomized trial comparing 4 thrombolytic strategies for acute myocardial-infarction. $N$ Engl J Med 1993; 329: 673-682.

17. Serruys PW, Unger F, Sousa JE, Jatene A, Bonnier H, Schonberger $\mathrm{J}$, et al. Comparison of coronary-artery bypass surgery and stenting for the treatment of multivessel disease. N Engl J Med 2001; 344: $1117-1124$.

18. Kinnaird TD, Stabile E, Mintz GS, Lee CW, Canos DA, Gevorkian $\mathrm{N}$, et al. Incidence, predictors, and prognostic implications of bleeding and blood transfusion following percutaneous coronary interventions. Am J Cardiol 2003; 92: 930-935.

19. Eikelboom JW, Mehta SR, Anand SS, Xie CC, Fox KAA, Yusuf $\mathrm{S}$. Adverse impact of bleeding on prognosis in patients with acute coronary syndromes. Circulation 2006; 114: 774-782.

20. Manoukian SV, Feit F, Mehran R, Voeltz MD, Ebrahimi R, Hamon M, et al. Impact of major bleeding on 30-day mortality and clinical outcomes in patients with acute coronary syndromes: An analysis from the ACUITY trial. J Am Coll Cardiol 2007; 49: $1362-1368$.

21. Mehran R, Pocock S, Nikolslcy E, Dangas GD, Clayton T, Claessen BE, et al. Impact of bleeding on mortality after percutaneous coronary intervention: Results from a patient-level pooled analysis of the REPLACE-2 (Randomized Evaluation of PCI Linking Angiomax to Reduced Clinical Events), ACUITY (Acute Catheterization and Urgent Intervention Triage Strategy), and HORIZONS-AMI (Harmonizing Outcomes With Revascularization and Stents in Acute Myocardial Infarction) trials. JACC Cardiovasc Interv 2011; 4: 654-664.

22. Mehran R, Pocock SJ, Nikolsky E, Clayton T, Dangas GD, Kirtane AJ, et al. A risk score to predict bleeding in patients with acute coronary syndromes. $J$ Am Coll Cardiol 2010; 55: 2556-2566.

23. Mamas MA, Anderson SG, Carr M, Ratib K, Buchan I, Sirker $\mathrm{A}$, et al. Baseline bleeding risk and arterial access site practice in relation to procedural outcomes after percutaneous coronary intervention. J Am Coll Cardiol 2014; 64: 1554-1564.

24. Andó G, Cortese B, Russo F, Rothenbhler M, Frigoli E, Gargiulo $\mathrm{G}$, et al. Acute kidney injury after radial or femoral access for invasive acute coronary syndrome management: AKI-MATRIX. $J$ Am Coll Cardiol 2017; 69: 2592-2603.

25. Pickering JW, Blunt IRH, Than MP. Acute kidney injury and mortality prognosis in acute coronary syndrome patients: A metaanalysis. Nephrology 2018; 23: 237-246.

26. Yeh RW, Secemsky EA, Kereiakes DJ, Normand SLT, Gershlick $\mathrm{AH}$, Cohen DJ, et al. Development and validation of a prediction rule for benefit and harm of dual antiplatelet therapy beyond 1 year after percutaneous coronary intervention. JAMA 2016; 315: $1735-1749$.

27. Baber U, Mehran R, Giustino G, Cohen DJ, Henry TD, Sartori $\mathrm{S}$, et al. Coronary thrombosis and major bleeding after PCI with drug-eluting stents risk scores from PARIS. $J$ Am Coll Cardiol 2016; 67: 2224-2234.

28. Natsuaki M, Morimoto T, Yamaji K, Watanabe H, Yoshikawa $\mathrm{Y}$, Shiomi H, et al. Prediction of thrombotic and bleeding events after percutaneous coronary intervention: CREDO-Kyoto thrombotic and bleeding risk scores. J Am Heart Assoc 2018; 7: 37.

29. Agostoni P, Biondi-Zoccai GGL, De Benedictis ML, Rigattieri S, Turri M, Anselmi M, et al. Radial versus femoral approach for percutaneous coronary diagnostic and interventional procedures: Systematic overview and meta-analysis of randomized trials. $J$ Am Coll Cardiol 2004; 44: 349-356.

30. Brueck M, Bandorski D, Kramer W, Wieczorek M, Holtgen R, Tillmanns $\mathrm{H}$. A randomized comparison of transradial versus transfemoral approach for coronary angiography and angioplasty. JACC Cardiovasc Interv 2009; 2: 1047-1054.

31. Nguyen P, Makris A, Hennessy A, Jayanti S, Wang A, Park K, et al. Standard versus ultrasound-guided radial and femoral access in coronary angiography and intervention (SURF): A randomised controlled trial. Eurointervention 2019; 15: e522-e530.

32. Watanabe H, Domei T, Morimoto T, Natsuaki M, Shiomi H, Toyota T, et al. Effect of 1-month dual antiplatelet therapy followed by clopidogrel vs 12-month dual antiplatelet therapy on cardiovascular and bleeding events in patients receiving PCI: The STOPDAPT-2 randomized clinical trial. JAMA 2019; 321: 24142427.

33. Mauri L, Kereiakes DJ, Yeh RW, Driscoll-Shempp P, Cutlip DE, Steg PG, et al. Twelve or 30 months of dual antiplatelet therapy after drug-eluting stents. $N$ Engl J Med 2014; 371: 2155-2166.

\section{Supplementary Files}

Please find supplementary file(s):

http://dx.doi.org/10.1253/circj.CJ-19-1117 